\title{
СРАВНИТЕЛЬНЫЙ АНАЛИЗ ЭФФЕКТИВНОСТИ ТРАДИЦИОННОГО ХИРУРГИЧЕСКОГО ЛЕЧЕНИЯ ПОСТЛУЧЕВЫХ РЕКТОВАГИНАЛЬНЫХ СВИЩЕЙ И ЛЕЧЕНИЯ С ИСПОЛЬЗОВАНИЕМ МИКРОИНЬЕКЦИОННОЙ АУТОТРАНСПЛАНТАЦИИ ТКАНЕЙ
}

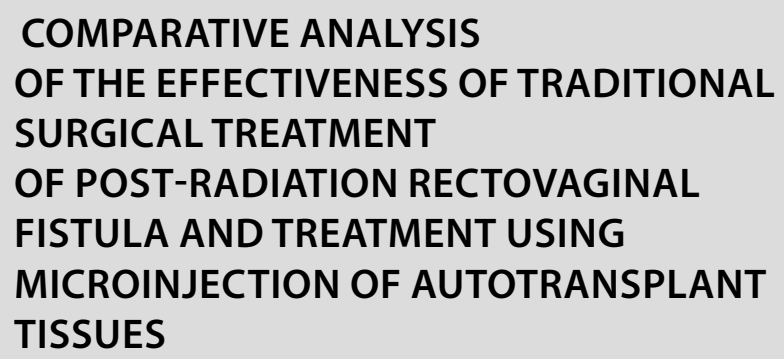

Zh. Teryushkova

V. Vasilyev

A. Vazhenin

S. Vasilyev

E. Lomakin

G. Dimov

Summary. Objectives. To conduct a comparative analysis of the effectiveness of traditional surgical treatment of postradiation rectovaginal fistula and treatment using microinjection autologous tissue transplantation.

Methods. The study involved 24 patients aged $54 \pm 10$ years with a diagnosis of postradiation rectovaginal fistula. As a medical method, the method of microinjection autotransplantation of adipose tissue was used. The efficacy analysis (case description) included data for all patients who underwent the procedure for administering autologous regenerative adipose tissue cells. In the form of lists (tables) for each patient, demographic data (age, gender) were presented, as well as the results of special examinations at the corresponding visit (before the procedure, after the procedure, 1, 3, 6, 12 months after the procedure, namely: research, anoscopy, sigmoidoscopy, colonoscopy, magnetic resonance imaging of the pelvis, endorectal ultrasound.

Results. The study found that when using the surgical method for the treatment of postradiation rectovaginal fistula, postoperative complications were observed in $42.1 \%$ of patients, which indicates the need to find alternative ways to treat this pathology. In particular, if before the procedure the average diameter of the fistula was $2.5 \pm$ $0.46 \mathrm{~cm}(\mathrm{M} \pm \mathrm{m})$, then after 3 months this indicator was $1.35 \pm 0.47$, and after 6 months $-1.12 \pm 0,47 \mathrm{~cm}$. All patients showed complete epithelization of the defect. Duration of observation - 1 year. During this period, complications and relapses did not occur.
Терюшкова Жанна Ивановна

К.м.н., МАУЗ ордена знак почета городская клиническая больница № 8, г. Челябинск

Васильев Вячеслав Сергеевич

К.м.н., ассистент, Южно-Уральский государственный медицинский университет Министерства

здравоохранения Российской Федерации, г. Челябинск

Важенин Андрей Владимирович

Академик РАН, д.м.н., профессор, Южно-Уральский государственный медицинский университет Министерства здравоохранения Российской Федерации; главный врач, Челябинский областной клинический центр онкологии и ядерной медицины, г. Челябинск

Васильев Сергей Александрович

Д.м.н., профессор, Южно-Уральский государственный медицинский университет Министерства здравоохранения Российской Федерации, г. Челябинск

Ломакин Евгений Алексеевич

Южно-Уральский государственный медицинский университет Министерства здравоохранения

Российской Федерачии, г. Челябинск

Димов Георгий Павлович

К.м.н., н.С., Южно-Уральский государственный медицинский университет Министерства здравоохранения Российской Федерации, г. Челябинск danil-popov97@mail.ru

Аннотация. Цель. Провести сравнительный анализ эффективности традиционного хирургического лечения постлучевых ректовагинальных свищей и лечения с использованием микроинъекционной аутотрансплантации тканей.

Материал и методы. В исследовании приняло участие 24 пациентки В в0зрасте $54 \pm 10$ лет с диагнозом постлучевой ректовагинальный свищ. В качестве лечебного применялся метод микроинъекционной аутотрансплантации жировой ткани. В анализ эффективности (описание случаев) были включены данные по всем пациентам, у которых была выполнена процедура введения аутологичных регенеративных клеток жировой ткани. В виде списков (таблиц) для каждого пациента были представлены демографические данные (возраст, пол), а также результаты специальных обследований на соответствующем визите (до процедуры, после процедуры, спустя 1, 3, 6, 12 месяцев после процедуры, а именно: бимануальное исследование, аноскопия, ректороманоскопия, колоноскопия, магнитно-резонанская томография малого таза, эндоректальное ультразвуковое исследование. 
Keywords: rectovaginal fistula, postradiation fistula, surgical method, microinjection, autologous tissue transplantation, method efficiency, tissue epithelization.

\section{Введение}

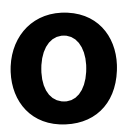
дним из наиболее распространенных методов лечения злокачественных новообразований малого таза, является лучевая терапия [1]. Зачастую последствием лучевой терапии являются функциональные и органические нарушения в мягких тканях, органах, прилегающих к зоне облучения. Большинство осложнений проявляются спустя довольно длительный промежуток времени после облучения (отдаленные последствия лучевой терапии) [2].

К поздним лучевым повреждениям следует отнести лучевые повреждения, которые возникают спустя 100 дней, и более после перенесенной лучевой терапии. В основе развития поздних лучевых повреждения лежит повреждение клеток и тканей на морфологическом уровне, что влечет за собой изменения структуры и функционального состояния поврежденных тканей. Лучевые повреждения представляют собой поэтапные изменения в структуре и функциональном состоянии тканей, окружающих опухоль.

Наименьшей толерантностью обладают стенки прямой кишки, поэтому одним из наиболее распространенных постлучевых осложнений являются такие заболевания, как ректиты, проктиты, при которых происходит, в первую очередь, повреждение прямой кишки [3]. Повреждение прямой кишки часто сопровождается вовлечением в патологический процесс всего кишечника, поскольку воспалительный процесс легко распространяется. При эндоскопическом исследовании лучевых повреждений кишечника, можно выявить характерные изменения кровеносных сосудов. Лечение постлучевых повреждений прямой кишки может быть, как традиционным, так и радикальным, в зависимости от тяжести патологических явлений, прогрессирования патологического состояния.
Результаты. В ходе исследования было установлено, что при использовании хирургического метода лечения постлучевых ректовагинальных свищей, послеоперационные осложнения наблюдались у 42,1\% пациенток, что указывает на необходимость поиска альтернативных путей лечения данной патологии. В частности, если до процедуры средний диаметр свища составлял

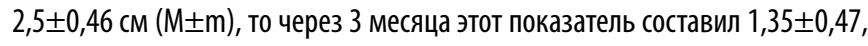
а через 6 месяцев - 1,12 0,47 см. У всех пациенток наблюдалась полная эпителизация дефекта. Сроки наблюдения - 1 год. За указанный период осложнений и рецидивов не возникало.

Ключевые слова: ректовагинальный свищ, постлучевой свищ, хирургический метод, микроинъекции, аутотрансплантация тканей, эффективность метода, эпителизация тканей.

Существуют различные классификации лучевых повреждений кишечника: катаральные, эрозивно-десквамативные, язвенные, свищевые. Наиболее характерным следствием проведенного лечения становится радиационный проктит, сопровождающийся слизистыми выделениями, диареей, ректальными кровотечениями, тенезмами, болевым синдромом, формированием свищей, рубцовыми стенозами, малигнизацией и пр.

Трудности в изложении жалоб, специфика необратимых поздних постлучевых изменений, рецидивирующее течение хронического лучевого проктита, несмотря на проводимую терапию, затрудняют своевременную диагностику, а, следовательно, и результаты лечения радиационного проктита [3].

По опубликованным данным, 5-10\% лучевых проктитов носят инфильтративно-язвенный характер, при этом ректальные язвы могут быть довольно обширными и проникать на всю толщу ректовагинальной перегородки [2; 3]. В 8-4,5\% случаев лучевые проктиты завершаются тяжелыми лучевыми повреждениями в виде ректовагинальных язв, которые затем переходят в ректовагинальные свищи [5].

В дальнейшем развивается ишемический некроз пораженных тканей [4].

Под ректовагинальным свищем (РВС), следует подразумевать тяжелое свищевое поражение ректовагинальной перегородки, при котором формируется сквозное отверстие между влагалищем и прямой кишкой. Последствия физический дискомфорт, резкое снижение качества жизни, болевые ощущения [6]. Обращает на себя внимание тот факт, что наиболее сложными, отдельно стоящей категорией, являются свищи постлучевые, развившиеся в результате лучевой терапии по поводу основного заболевания (рака органов малого таза). Постлучевые свищи выделяют 
в отдельную категорию, поскольку это сложнейшая нозология, которая требует специфического подхода и к диагностике, и к лечению. Они довольно сложно поддаются лечению, практически не заживают самопроизвольно, характеризуются склонностью к рецидивирующему течению [7]. Консервативное лечение постлучевых свищей в подавляющем числе наблюдений неэффективно, однако некоторые авторы рекомендуют проводить его при небольших размерах свища (до 0,5 см) и в первые 12 месяцев с момента его появления [8]. Тактика лечения лучевых прямокишечно-влагалищных свищей почти всегда требует наложения колостомы для уменьшения воспалительных процессов в области свища [4]. Ряд авторов сходится во мнении, что наложение трансверзостомы более целесообразно, чем сигмостомы [4; 5; 6; 7]. Известно, что основным методом лечения РВС в настоящее время является хирургическое лечение. К недостаткам хирургического метода лечения относят: высокий риск развития послеоперационных осложнений, рецидивов, возможность инфицирования, длительное послеоперационное восстановление [7]. Еще один недостаток состоит в том, что часто возникает потребность постановке разгрузочной колостомы [4].

У пациенток с постлучевыми ректовагинальными свищами, часто возникает потребность в проведении хирургического вмешательства в объеме экзертерации таза, фистулопластики [8]. Послеоперационные осложнения при лечении лучевых повреждений прямой кишки наблюдаются у 42,1\% пациенток. Это довольно высокий показатель, который указывает на недостаточную эффективность хирургических методов в лечении постлучевых осложнений прямой кишки. Все это указывает на необходимость поиска альтернативных путей решения проблемы [7; 9]. В качестве альтернативы может выступать микроинъекционная техника аутотрансплантации регенераторных клеток жировой ткани. Аутологичные регенеративные клетки жировой ткани находят широкое применение в современной медицине $[10 ; 11 ; 12 ; 13 ; 14 ; 15 ; 16]$.

Тем не менее, до сих пор не было разработано единого протокола, который позволил бы с максимально высокой точностью и эффективностью проводить лечение пациенток с использованием лечения с использованием микроинъекционной аутотрансплантации тканей [17; 18; 19; 20]. Нет комплексных исследований, в которых была бы проведена оценка эффективности данного метода, в особенности, в сравнении с альтернативными методами. Именно это и определило выбор темы исследования.

\section{Це^ь}

Провести сравнительный анализ эффективности традиционного хирургического лечения постлучевых ректовагинальных свищей и лечения с использованием микроинъекционной аутотрансплантации тканей.

\section{Материа^ и метомы}

Исследование выполнялось на базе ГБУЗ «Челябинский областной клинический центр онкологии и ядерной медицины» и МАУЗ ОЗП ГКБ № 8 в период с 2016 по 2019 гг. Пациенты принимали участие в проекте на протяжении года; наблюдение за каждым пациентом продолжалось 6 месяцев. Таким образом, общая продолжительность клинической работы составляет 18 месяцев.

В исследовании приняло участие 24 пациентки в возрасте $54 \pm 10$ лет с диагнозом постлучевой ректовагинальный свищ. Эти пациентки составили экспериментальную группу. Материал вводили в патологически измененные ткани с целью восстановления нормальной регенерации. В качестве лечебного применялся метод микроинъекционной аутотрансплантации жировой ткани. Результаты лечения сравнивались с уже существующими традиционными методами лечения и методами лечения, используемыми в хирургии. Для контроля было взято 24 человека, которым проводилось лечение с применением различных хирургических методов лечения ректовагинального свища. Каждая пациентка проходила обследование, как минимум, 5 раз (5 визитов). 1-й визит в день манипуляции (визит включает подготовку аутологичных регенеративных клеток жировой ткани (adipose-derived regeneratory cells, ADRC) и их инъекцию, дальнейшее наблюдение в течение 5 дней, выписка из стационара на 4-5 день). Затем 2 визит через месяц; 3 визит через три месяца; 4 визит через шесть месяцев; 5 визит через год. Для подтверждения диагноза рак прямой кишки использовались общепризнанные достоверные классификации постановки диагноза (МКБ-10). Для подтверждения диагноза применялись стандартные методы исследования, в том числе лабораторные и инструментальные исследования, гистологический анализ образцов ткани, полученных при биопсии.

В анализ эффективности (описание случаев) были включены данные по всем пациентам, у которых была выполнена процедура введения аутологичных регенеративных клеток жировой ткани. В виде списков (таблиц) для каждого пациента были представлены демографические данные (возраст, пол), а также результаты специальных обследований на соответствующем визите, а именно: бимануальное исследование; аноскопия; ректороманоскопия; колоноскопия; магнитно-резонанская томография малого таза; эндоректальное ультразвуковое исследование.

\section{Статистика}

При анализе данных в работе использовались стандартные методы вариационной статистики. Статистиче- 
Таблица 1. Доля (\%) осложнений при традиционном хирургическом лечении ректовагинальных свищей

\begin{tabular}{|l|l|l|}
\hline Вид осложнения & $\begin{array}{l}\text { Доля (\%) от общего числа } \\
\text { пациенток (n=21) }\end{array}$ & $\begin{array}{l}\text { Купировано } \\
\text { консервативно,\% }\end{array}$ \\
\hline Острый парапроктит & 5,3 & 5,3 \\
\hline Острый геморрой, тромбоз геморроидальных узлов & 5,3 & 5,3 \\
\hline Нагноение операционной раны & 10,5 & 5,3 \\
\hline Дизурические расстройства & 15,8 & 15,8 \\
\hline Прорезывание швов раны влагалища & 10,5 & 5,3 \\
\hline Резистентные к лечению воспалительные инфильтраты & 15,8 & 10,5 \\
\hline Болезненные половые акты (диспареуния) & 5,3 & 5,3 \\
\hline $\begin{array}{l}\text { Проявления обструктивной дефекации, неполное опорожнение } \\
\text { прямой кишки }\end{array}$ & 21,1 & 10,5 \\
\hline Рецидив заболевания & 21,1 & 15,8 \\
\hline
\end{tabular}

Таблица 2. Оценка диаметра ректовагинальных свищей в динамике после проведения микроинъекционной аутотрансплантации жировой ткани, $\mathrm{n}=24$

\begin{tabular}{|l|l|l|l|l|l|}
\hline Показатель & До процедуры & Через 3 месяца & Через 6 месяцев & Через 1 год & Количество процедур инъекций \\
\hline Среднее значение, см. & 2,5 & 1,35 & 1,12 & 0 & 3 \\
\hline Минимум, см. & 0,4 & 0,1 & 0 & 0 & 2 \\
\hline Максимум, см & 4 & 1,8 & 1,5 & 0 & 5 \\
\hline
\end{tabular}

Таблица 3. Сравнительный анализ эффективности хирургического лечения и микроинъекционного метода

\begin{tabular}{|l|l|l|}
\hline & Хирургическое лечение & Микроинъекционный метод \\
\hline Осложнения & $42,1 \%$ & 0 \\
\hline $\begin{array}{l}\text { Потребность в постановке разгрузочной } \\
\text { колостомы }\end{array}$ & Есть & Нет \\
\hline $\begin{array}{l}\text { Проявления обструктивной дефекации, } \\
\text { неполное опорожнение прямой кишки }\end{array}$ & $21,1 \%$ & 0 \\
\hline Рецидивы & $21,1 \%$ & 0 \\
\hline
\end{tabular}

ская обработка данных производилась с использованием стандартного пакета MS Excel 2007. Рассчитывали среднее, стандартное отклонение, ошибку, медиану. Также был проведен корреляционный и регрессионный анализ, определены тренды.

\section{Результаты}

Для получения сведений об особенностях течения послеоперационного периода, о возникших осложнениях, были проанализированы истории болезней пациенток, их анамнез. Результаты представлены в таблице 1.

Как видим из таблицы, частота различных осложнений при применении хирургических методов лечения колеблется в пределах от 5,3 до 21,1\%. Рецидивы заболевания наблюдались в 21,1\% случаев. Все это указывает на недостаточную эффективность хирургических методов в лечении постлучевых ректовагинальных свищей, и говорит о необходимости поиска альтернативных методов лечения.

Одним из альтернативных методов может стать метод микроинъекционной аутотрансплантации жировой ткани.

В период с 2016 по 2019 год, в рамках пилотного клинического исследования проведена апробация указанного метода. Для проведения микроинъекций использовались аутологичные клетки жировой ткани.

По результатам клинического исследования проанализирована динамика состояния ректовагинальных свищей у пациенток: оценка размера (диаметр) свища 
до процедуры, на промежуточной стадии - через 3 месяца и спустя 6 месяцев после процедуры. Данные представлены в табл. 2.

При анализе представленных в таблице результатов отмечается прогрессивное улучшение состояния свища. Так, если до процедуры средний диаметр свища состав-

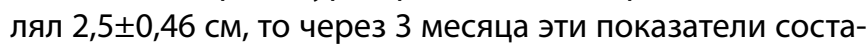

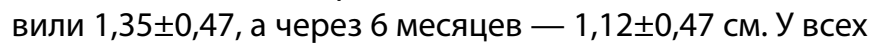
пациенток наблюдалась полная эпителизация дефекта через 1 год. В среднем, для достижения полной эпителизации постлучевого ректовагинального свища, потребовалось 3 процедуры инъекции аутологичной СВФ жировой ткани. В наиболее тяжелых случаях применялось 5 процедур инъекций. Минимальное число инъекций, которое потребовалось для достижения полной эпителизации свищевого дефекта, составило 2 процедуры. Полученные данные указывают на эффективность проведенной терапии (таблица 3).

При сравнении результатов, полученных до проведения процедуры, и показателей, полученных спустя 3 месяца после проведенной процедуры, можно отметить положительную динамику заживления ректовагинального свища. Также прослеживается положительная динамика при сравнении показателей, полученных спустя 3 месяца после проведения процедуры, и спустя 6 месяцев после процедуры. Все это указывает на наличие положительной динамики в лечении, и свидетельствует об эффективности лечения ректовагинальных свищей с применением аутологичной жировой ткани.

Была проведена оценка динамики состояния постлучевых ректовагинальных свищей спустя 3 месяца и спустя 6 месяцев после проведения процедуры. Отмечается уменьшение размеров ректовагинального свища в динамике спустя 3 месяца, и спустя 6 месяцев. По сравнению с данными, полученными до проведения процедуры, спустя 3 месяца отмечено снижение размеров дефекта в 3 раза. Зарегистрировано дальнейшее уменьшение размера дефекта до 0,2 см и ниже. Спустя 6 месяцев отмечается снижение диаметра дефекта постлучевых повреждений примерно в 7-7,5 раз по сравнению с исходными данными. В динамике регистрируется уменьшение диаметра дефекта, вплоть до его полного исчезновения (достижения полной эпителизации).

До применения микроинъекционного метода, размер ректовагинального свища находился в пределах от 0,4 до 4 см, спустя три месяца размер дефекта стал находиться в пределах от 0,1 до 1,5 см. Спустя 6 месяцев после процедуры размер дефекта стал находиться в интервале от 0 до 1,8 см, то есть, спустя 6 месяцев у многих пациенток уже отмечались случаи полной эпителизации ректовагинального свища.

\section{Обсужление}

Сопоставление результатов хирургического лечения и микроинъекционного метода показало свою эффективность. Микроинъекционную тактику можно считать альтернативной хирургическому лечению, поскольку она позволяет достичь полной эпителизации поврежденной ткани, исключает вероятность развития рецидивов, предотвращает риск развития осложнений, в том числе, риск постоперационного инфицирования раневой поверхности, некроза. Существенно снижается продолжительность восстановительного периода. Наиболее вероятной причиной полученных результатов является отличие принципов и механизмов действия рассматриваемых методов.

Полученные нами данные сопоставимы с литературными данными. К настоящему времени накоплен клинический опыт успешного использования микроинъекционной аутотрансплантации тканей (липографтинг, липофилинг) для лечения поздних лучевых повреждений мягких тканей различных локализаций, что и послужило для нас стимулом к использованию этой методики в сложной клинической ситуации у больной с постлучевым коловагинальным свищом. Аутологичная трансплантация жировой стромальной сосудистой фракции (SVF) является экономически эффективным и технически доступным вариантом для клеточной терапии [10].

Beche-Adams T.H. [21] сообщает об итогах трансплантации липоаспирата при хронических анальных трещинах и ректовагинальных свищах. В это исследование были включены восемь пациентов с множественными дефектами. Перианальная аутологичная трансплантация жира может быть выполнена для лечения сложных анальных трещин и свищей. Данный метод хорошо переносится и дает обнадеживающие результаты [21].

\section{Зак^ючение}

Результаты сравнительного анализа эффективности хирургического лечения и микроинъекционного метода указывают на то, что более эффективным является второй. Так, частота различных осложнений при применении хирургических методов лечения колеблется в пределах от 5,3 до 21,1\%. Рецидивы заболевания наблюдались в 21,1\% случаев. При использовании микроинъекционной техники регистрируется уменьшение диаметра дефекта, вплоть до его полного исчезновения (достижения полной эпителизации). Полная эпителизация достигается через 1 год, в среднем требуется от 3 до 5 инъекций аутологичных клеток жировой ткани. Рецидивов и осложнений не возникает. 


\section{ЛИТЕРАТУРА}

1. Каприн А. Д., Старинский В. В., Петрова Г. В., ред. Состояние онкологической помощи населению России в 2017 году. Москва, РФ: МНИОИ им ПА Герцена; 2018. 236 c. http://www.oncology.ru/service/statistics/condition/2017.pdf

2. Пасов В. В., Бардычев М. С., Терехов О. В. Лечение поздних лучевых циститов у онкологических больных. Обнинск, РФ; 2007.20 с.

3. Бардычев М. С. Лучевые повреждения прямой кишки после терапии рака шейки матки с применением шлангового аппарата «Агат-В» и их лечение. Мед. радиология. 1981; 4: 28-31.

4. Zi-Xu Y., Teng-Hui M., Huai-Ming W. Colostomy is a simple and effective procedure for severe chronic radiation proctitis. World J Gastroenterol 2016; 22(24): 5598608.

5. Стрельников В. Н., Дульцев Ю. В., Саламов К. С. Хирургическое лечение прямокишечно-влагалищных свищей. Хирургия. 1980; 9: 103-108: 45.

6. арташев А. А., Смолькина А. В., Макаров С. В., Дёмин В.П., Барбашин С. И., Мидленко И. И. Опыт лечения ректовагинальных свищей. Междунар. Жур.н Прикладных и Фундам. Исследований. 2017; (12 ч 2):282-86.

7. Семирджанянц Э. Г., Петровский А. В., Фанштейн И. А., Нечушкин М. И., Геворкян В. С., Автомонов Д. Е. Хирургическая реабилитация больных с постлучевыми ректо-вагинальными свищами при раке шейки матки. Колопроктология. 2013;(4):13-17. http://www.gnck.ru/pdf/journal_4_46_2013.pdf

8. Елисеев Д.Э., Елисеев Э. Н., Аймамедова 0. Н. Хирургическое лечение ректовагинальных свищей. Опыт пластики лучевого ректовагинального свища лоскутом Martius-Symmonds. Онкогинекология 2015; 2: 59-69.

9. Александров В.Б., Корнев Л. В., Разбирин В. Н., Сологубов В. В., Горшков В.С., Боленко Р. А. Результаты применения лапароскопической технологии при хирургическом этапе лечения злокачественных опухолей нижнеампулярного отдела прямой кишки. Бюллетень ВСНЦ СО РАMН. 2018; 4 (80): 11-15.

10. Norderval S., Lundby L., Hougaard H., Buntzen S., Weum S., de Weerd L. Efficacy of autologous fat graft injection in the treatment of anovaginal fistulas. Tech Coloproctol. 2018 Jan;22(1):45-51.

11. Sanz-Baro R., García-Arranz M., Guadalajara H., de la Quintana P., Herreros M. D., García-Olmo D. First-in-Human Case Study: Pregnancy in Women With Crohn's Perianal Fistula Treated With Adipose-Derived Stem Cells: A Safety Study. Stem Cells Transl Med. 2015 Jun;4(6):598-602.

12. Shiffman M. A., Di Giuseppe A., Bassetto F., eds. Stem cells in aesthetic procedures: art, science, and clinical techniques. Berlin: Springer; 2014.822 p.

13. Рачинская 0. А., Меркулов В. А. Применение методов цитогенетического анализа при оценке качества клеточных линий в составе биомедицинских клеточных продуктов. БИОпрепараты. Профилактика, диагностика, лечение. 2018; 18(1): $25-32$.

14. Астрелина Т. А., Гомзяков А. Е., Кобзева И. В. Оценка качества и безопасности применения криоконсервированных мультипотентных мезенхимальных стромальных клеток плаценты в клинической практике. Клеточная трансплантология и тканевая инженерия. 2013; Т. 8; 4: 82-87.

15. Веремеев А. В., Болгарин Р. Н., Петкова М. А. Стромально-васкулярная фракция жировой ткани как альтернативный источник клеточного материала для регенеративной медицины. Гены \& клетки. 2016; 11(1):1-8.

16. Смышляев И. А., Гильфанов С. И., Копылов В. А. Оценка безопасности и эффективности внутрисуставного введения стромально-васкулярной фракции жировой ткани для лечения гонартроза: промежуточные результаты клинического исследования. Травматология и ортопедия России. 2017;23(3):17-31.

17. Kuo Y. R., Wang C. T., Cheng J. T., Kao G. S., Chiang Y.C., Wang C. J. Adipose-derived stem cells accelerate diabetic wound healing through the induction of autocrine and paracrine effects. Cell Transplant. 2016; 25(1):71-81.

18. You D., Jang M. J., Kim B. H., Song G., Lee C., Suh N., Jeong I. G., Ahn T.Y., Kim C. Comparative study of autologous stromal vascular fraction and adiposederived stem cells for erectile function recovery in a rat model of cavernous nerve injury. Stem Cells Transl Med. 2015;4(4):351-358.

19. Dellis A., Papatsoris A. Stem cell therapy for the treatment of Peyronie's disease. Expert Opin Bio ITher. 2017;17(4):407-413.

20. Badimon L., Oñate B., Vilahur G. Adiposederived Mesenchymal Stem Cells and Their Reparative Potential in Ischemic Heart Disease. Rev EspCardiol. 2015;68(7):599_ 611.

21. Beche-Adams T. H. Rectovaginal fistulas. Clin. Colon. Rectal. Surg. 2010; 2: 99-1.

() Терюшкова Жанна Ивановна, Васильев Вячеслав Сергеевич,

Важенин Андрей Владимирович, Васильев Сергей Александрович,

Ломакин Евгений Алексеевич, Димов Георгий Павлович ( danil-popov97@mail.ru ).

Журнал «Современная наука: актуальные проблемы теории и практики» 